\title{
The Relationship Between ISO 17025 Quality Management System Accreditation and Laboratory Performance
}

\author{
Esin Sadikoglu and Talha Temur \\ Gebze Institute of Technology, \\ Turkish Standard Institution, \\ Turkey
}

\section{Introduction}

International Organization for Standardization ISO 9000 is a general standard related to fundamentals of implementation of a quality management system. The aim of ISO 9000 is to implement quality management procedures by means of leadership, work instructions, documentation and record keeping. ISO 9000 standard does not determine the quality or performance level of the product or service. It deals with standardization of process management and improvement of an organization. The origin of ISO 9000 standards comes from harmonizing quality standards across nations (Heizer \& Render, 2011; Goetsch \& Davis, 2010).

Laboratory accreditation assesses the competencies of all types of laboratories in terms of performing specific tests and calibrations. ISO and the international Electro-Technical Commission (IEC) introduced ISO/IEC 17025 standard due to the growing importance of accreditation and international recognition. The assessment of the facilities that calibrate and test equipment is crucial to monitor accuracy of measurement and testing (Beckett and Slay, 2011). ISO 17025 is a laboratory standard equivalent to more generic ISO 9000 . The standard can be applied by all organizations performing tests and/or calibrations and it can harmonize laboratories worldwide (ISO-9000, 2010).

ISO 17025, as all ISO standards, heavily focuses on documenting the process of any analysis performed by a laboratory. It includes the quality management system and technical requirements of the accreditation process. The management requirements section of the standard evaluates the organization of the laboratory; its quality system; document control; review of requests; tenders and contracts; subcontracting of tests and calibrations; purchasing services and supplies; service to the customer; complaints; control of nonconforming testing and/or calibration work; corrective actions; preventive actions; improvement; control of records, internal audits and management reviews. This section adapts the ISO 9000 quality management criteria into a laboratory context. The technical requirements section of the ISO 17025 standard evaluates personnel; accommodation and environmental conditions; test and calibration methods and method validation; equipment; measuring traceability; sampling; handling of test and calibration items; assurance of the quality of test and calibration results, and reporting the results. A laboratory must identify both the management requirements and technical requirements of the standard in order to 
produce a good product and satisfy its customer (ISO/IEC-17025, 2010). Although ISO standards and total quality management implementations have the same objective of improving competitiveness of the organization, they are not interchangeable. They are compatible with and support each other. However, the majority of ISO certified organizations do not fully implement total quality (Goetsch \& Davis, 2010).

As with ISO 9000 (Goetsch \& Davis, 2010), ISO 17025 is not prescriptive in its content. In other words, the standard does not insist a laboratory pursue the methods nor does it determine the qualifications of the staff to perform a test or calibration. It lets the laboratory determine and document its own standards needed. Then the standard ensures the laboratory comply with the standards set by the laboratory (Beckett and Slay, 2011).

There is a need to compare the laboratories' experimental measurement results for monitoring and assessing their performance. However, there are limited studies as well as ambiguous and mixed results of the relationship between ISO 17025 accreditation and laboratory performance in literature. This study contributed to figure out the effect of the adoption of ISO 17025 accreditation of a laboratory on its performance. The paper is organized as follows: Section 1 introduces ISO 17025 standard and the importance of study. Section 2 presents previous studies about ISO 17025 accreditation implementations and laboratory performance. Section 3 gives methodology of the study including data collection and methods of analysis. Section 4 presents results of the analysis, discussion, and implications of the study. Final section concludes the paper.

\section{Literature review}

Laboratory accreditation can help laboratories to produce consistent results by means of implementing the framework of a documented quality system (Beckett and Slay, 2011).

Cooper, Moeller, \& Kronstrand (2008) presented the current status of accreditation of hair testing laboratories based in Europe. They found 48 percent of the laboratories accredited and 31 percent of the laboratories accredited to ISO 17025.

Malkoc \& Neuteboom (2007) found approximately 67 percent of government or police laboratories were not accredited. They claimed there was ambiguity of perceptions about the meaning, purpose, and principles of quality assurance and accreditation among European forensic science laboratories. The personnel of some laboratories did not know the fact that a laboratory without having a quality management system cannot get accredited. This problem is attributed to "lack of awareness syndrome."

There are mixed results about the relationship between ISO 17025 accreditation and laboratory performance. Zaretzky (2008) claims the improper use of quality management tools in the laboratory has a negative effect on laboratory activity especially on continous improvement implementation. This also always a negative effect on the customer.

Guntinas et al. (2009) performed proficiency test for heavy metals in feed and food of 31 laboratories, 28 of which were ISO 17025 accredited laboratories, in Europe. They found low laboratory performance and claimed the errors in measurement uncertainity might be the reason of failure of the laboaratories.

Raposo et al. (2009) conducted proficiency testing of chemical oxygen demand measurements and found low laboratory performance. They claimed the failure might come from heterojenity of the samples, meaurement errors, and the differences in the analysis methods. 
Korun \& Glavic-Cindro (2009) made an analysis of the causes of discrepant results in proficiency tests in a testing laboratory and investigated the reasons of erroneous laboratory results in the years of 2003 and 2007.

Ahmad, Khan, \& Ahmad (2009) investigated accreditation process and standardization of Pathology Laboratories in Pakistan. They claimed physical conditions and limited qualified workforce were the reasons of current insufficient accreditation status in Pakistan.

Uras (2009) exlained quality regulations and accreditation standards for clinical chemistry in Turkey. He mentioned insufficient accreditation status in clinic laboratories and emphasized the importance of having a necessary infrastructure and directions in the healhtcare in Turkey.

On the other hand, there are successful implementations of accreditation reported in the literature. Iglicki, Mila, Furnari, Arenillas, Cerutti, \& Carballido (2006) showed accreditation process of the Quality System by ISO 17025 standards in a national reference laboratory of Argentina. They found the implementation improved systematic recording and control of the tasks, robustness of the traceability chain and external recognition of quality of the laboratory.

Cortez (1999) found accredited laboratories had more satisfactory and less suspicious and unsatisfactory laboratory performances than non-accredited laboratories. Thus, they claimed accredited laboratories were more succesful than non-accredited laboratories.

Hall, Maynard, \& Foster (2003) have explained implementations of ISO 17025 accreditation of a laboratory within racing chemistry in Britain. They reported successful results in spite of difficulties of implementation of accreditation.

Vlachos, Michail, \& Sotiropoulou (2002) presented implementation and maintance of the ISO 17025 quality assurance system in the General Chemical State Laboratory of Greece. The laboratory could prove the reliability of the test results and technical competence to clients and regulators. They experienced that accreditation and international quality standard of the laboratory improved its competitiveness. The laboratory could fulfill the requirements of clients and regulators. The laboratory could effectively analyze, solve and reduce operational problems with the adoption of a quality culture. The laboratory obtained employee fulfillment with the personnel training and teamwork. Based on the reviewed literature, we propose the following hypothesis:

H1: The existence of ISO 17025 accreditation affects laboratory performance.

We tested this hypothesis in all laboratories, as well as in each sector namely manufacturing, private, state, building materials, chemical, electro-magnetic conformity (EMC), metallic material and textile laboratories, separately.

There were 1 million ISO 9000 certified firms in 175 countries by 2009 (Heizer \& Render, 2011). Table 1 and Figure 1 shows accreditation status of countries with respect to the number of accredited laboratories per million people of each country as of 2010. The numbers of accredited laboratories were obtained from the web pages of the national accreditation institutions of the countries given in the table and figure. As clearly noticed in the table and figure, Australia (98.3) and Singapore (84.3) have the most accredited laboratories and Turkey (4.4) has the least accredited laboratories per million people. 


\begin{tabular}{|l|c|c|c|}
\hline Country & $\begin{array}{l}\text { Number of } \\
\text { accredited } \\
\text { laboratories }\end{array}$ & Population (million) & $\begin{array}{l}\text { Laboratory/population } \\
(\# / \text { million people) }\end{array}$ \\
\hline Turkey & 316 & 72.0 & 4.4 \\
\hline Australia & 2065 & 21.0 & 98.3 \\
\hline Denmark & 160 & 5.5 & 29.1 \\
\hline France & 1700 & 64.0 & 26.6 \\
\hline Germany & 2290 & 82.0 & 27.9 \\
\hline Hong Kong & 170 & 7.0 & 24.3 \\
\hline Norway & 145 & 4.5 & 32,2 \\
\hline Singapore & 295 & 3.5 & 84,3 \\
\hline Spain & 780 & 41.0 & 19,0 \\
\hline Czech Republic & 610 & 10.0 & 61,0 \\
\hline England & 1970 & 61.0 & 32,3 \\
\hline Italy & 926 & 58.0 & 16,0 \\
\hline Sweden & 585 & 9.0 & 65,0 \\
\hline
\end{tabular}

Table 1. Accreditation status of some countries.

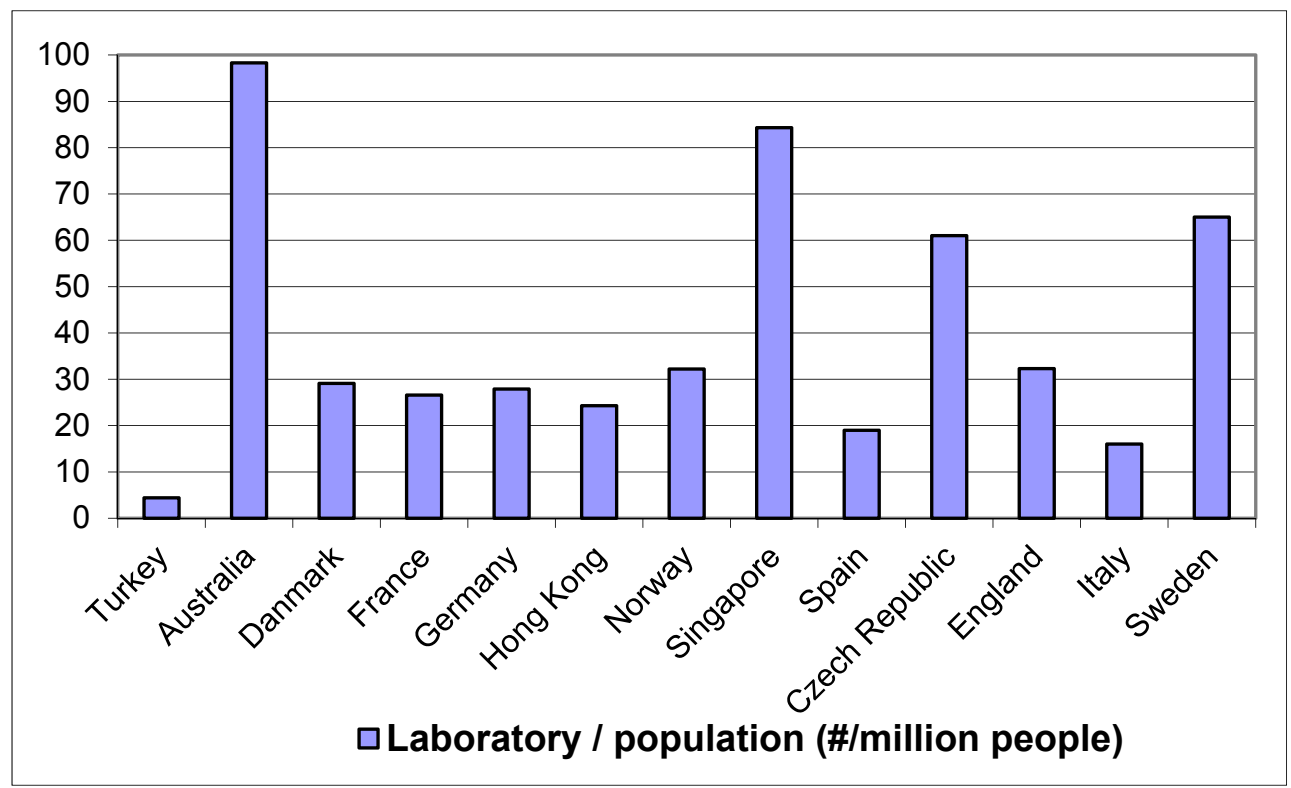

Fig. 1. Accreditation status of some countries.

\section{Methodology}

Experiment Laboratory Center of the Turkish Standards Institution is the only member of the European Proficiency Testing Information system (EPTIS) (TSE, 2010). The study was informed in the web pages of Turkish Standards Institution as well as by telephone and email to laboratories in March 2009. The study used 36 experiment program, some of which 
require multiple laboratory measurements. For example, Experiment Program 8 required eight different laboratory measures.

Laboratories were classified with respect to organizational structure namely, manufacturing, private, and state laboratories for the analysis. They were also classified with respect to industry sector, namely building materials, chemical, electro-magnetic conformity (EMC), metallic materials and textile laboratories.

Laboratory performance measures were standardized for the analysis since the measures were different in different industry sectors. The laboratory performance measures were classified as satisfactory $(|z| \leq 2)$, suspicious $(2<|z|<3)$ and unsatisfactory $(|z| \geq 3)$ to compare laboratories' frequencies of performances. The absolute standard values of the laboratory measurements of greater than $10(|z|>10)$ were discarded for improving reliability. Grubbs test was used for determining and discarding the extreme values from the analysis. In addition, Cochran test was used for confirming homogeneity of variance of laboratories before conducting t-test (Ferrero \& Casaril, 2009).

Data were analyzed with frequency comparison; t-test and Welch test with respect to existence of ISO 17025 accreditation of the laboratories. The assumptions of the independent-sample t-test were satisfied before the analysis. For this purpose, KolmogorovSmirnov test was used for testing normality of the data and Levene's test was used for testing homogeneity of variance of the data. Welch test was conducted to compare means of the two groups when homogeneity of variance assumption was not satisfied according to Levene's test results.

\section{Results of the analysis and discussion}

The study obtained 564 laboratory measurements from participating 73 laboratories in different sectors located 20 cities in Turkey. Most of the participant laboratories $(68.5 \%)$ conducted one to three experiment programs. The participant laboratories represented Turkish economy since the regional dispersion of the participants was similar to the entrepreneur (manufacturing) numbers according to business registration in 2008 (TUIK, 2010).

Most of the participant laboratories were manufacturing laboratories (46.6\%) and state laboratories $(32.9 \%)$. The number of ISO accredited laboratories $(31,42.5 \%)$ was close to the number of non-ISO accredited laboratories (34, 46.6\%). Most of the ISO accredited laboratories $(58.1 \%)$ were state laboratories while most of non-ISO accredited laboratories $(73.5 \%)$ were manufacturing laboratories.

Kolmogorov-Smirnov test results confirm that normality assumptions were satisfied. Table 2 gives comparison results of laboratory performance percentages with respect to ISO 17025 accreditation existence. Data in the table are in percentages. The first data in the cells are satisfactory laboratory performance $(|z| \leq 2)$ percentages and the second data given in the parentheses are unsatisfactory laboratory performance $(|z| \geq 3)$ percentages. Table 3 gives independent sample t-test or Welch test results of laboratory performance.

Table 2 shows that satisfactory laboratory performances of ISO accredited laboratories range from 71.7 to 100 percent and their unsatisfactory laboratory performances range from 0 to 20.8 percent. On the other hand, satisfactory laboratory performances of non-ISO accredited 
laboratories range from 65.2 to 100 percent. Their unsatisfactory laboratory performances range from 0 to 11.1 percent.

\begin{tabular}{|l|c|c|}
\hline \multirow{2}{*}{ Laboratories } & \multicolumn{2}{|c|}{ ISO 17025 Accreditation Existence } \\
\cline { 2 - 3 } & ISO Accredited (\%) & Non-ISO Accredited (\%) \\
\hline All laboratories & $85.8^{a}\left(11.7^{b}\right)$ & $86.3(7.7)$ \\
\hline Manufacturing laboratories & $83.1(16.9)$ & $91.4(6.7)$ \\
\hline Private laboratories & $71.7(20.8)$ & $65.2(4.3)$ \\
\hline State laboratories & $94.8(2.9)$ & $86.1(11.1)$ \\
\hline Building materials laboratories & $92.5(5.0)$ & $88.1(9.5)$ \\
\hline Chemical laboratories & $100.0(0.0)$ & $87.5(8.3)$ \\
\hline EMC laboratories & $78.1(19.5)$ & $78.0(4.9)$ \\
\hline Metallic materials laboratories & $88.0(8.0)$ & $91.7(8.3)$ \\
\hline Textile laboratories & $97.2(0.0)$ & $100.0(0.0)$ \\
\hline
\end{tabular}

a. Satisfactory laboratory performance $(|z| \leq 2)$ percentage

b. Unsatisfactory laboratory performance $(|z| \geq 3)$ percentage

Table 2. Laboratory performance percentages comparison results.

As clearly noticed in Tables 2 and 3, the existence of ISO 17025 accreditation of a laboratory statistically significantly affects laboratory performance in all laboratories, manufacturing laboratories and EMC laboratories in a negative way. In other words, non-ISO 17025 accredited laboratories, in general, have higher satisfactory laboratory performance $(|z| \leq 2)$ and lower unsatisfactory laboratory performance $(|z| \geq 3)$ than ISO 17025 accredited laboratories in all, manufacturing and EMC laboratories. Furthermore, existence of ISO 17025 accreditation does not statistically significantly affect laboratory performance in the other sectors.

\begin{tabular}{|c|c|c|c|c|}
\hline Laboratories & Statistics & $\begin{array}{c}\text { Degree of } \\
\text { freedom }\end{array}$ & $\begin{array}{c}\text { Significance } \\
\text { (two-tailed) level }\end{array}$ & $\begin{array}{c}\text { State of the } \\
\text { hypothesis }\end{array}$ \\
\hline All & $2.86^{a}$ & 358.07 & 0.09 & Supported \\
\hline Manufacturing & $2.97^{a}$ & 64.05 & 0.09 & Supported \\
\hline Private & $0.75^{b}$ & 74.00 & 0.46 & Not supported \\
\hline State & $-0.67^{b}$ & 208.00 & 0.50 & Not supported \\
\hline Building materials & $0.97^{b}$ & 122.00 & 0.33 & Not supported \\
\hline Chemical & $0.68^{a}$ & 33.71 & 0.42 & Not supported \\
\hline EMC & $3.74^{a}$ & 114.97 & 0.06 & Supported \\
\hline Metallic materials & $-1.06^{b}$ & 35.00 & 0.30 & Not supported \\
\hline Textile & $-1.49^{b}$ & 76.00 & 0.14 & Not supported \\
\hline
\end{tabular}

a. Asymptotically F distributed; Welch test was used.

b. Independent samples t-test was used.

Table 3. Independent sample t-test or Welch test results of laboratory performance. 
The results (Tables 2 and 3) show that all ISO accredited laboratories, in general, have lower satisfactory laboratory measures $(85.8 \%)$ and higher unsatisfactory laboratory measures $(11.7 \%)$ than non-ISO accredited laboratories (86.3\% and $7.7 \%$, respectively).

Furthermore, ISO 17025 accredited manufacturing laboratories have, in general, produce less satisfactory laboratory measures $(83.1 \%)$ and more unsatisfactory laboratory measures (16.9\%) than non-ISO 17025 accredited manufacturing laboratories $(91.4 \%$ and $6.7 \%$, respectively). Results imply that manufacturing laboratories cause the negative effect of ISO 17025 accreditation on laboratory performance. Manufacturing laboratories measure the products of their host companies. Thus, ISO accredited manufacturing laboratories may not be careful in measurement and they may give more erroneous results than non-ISO accredited manufacturing laboratories.

Moreover, ISO 17025 accredited EMC laboratories, in general, give more unsatisfactory laboratory measures (19.5\%) than non-ISO accredited EMC laboratories (4.9\%) although their performances of satisfactory laboratory measures are close to each other.

ISO certification has some benefits: Periodic audits give pressure the firms to maintain conformance to the requirements of the standard. In addition, certified organizations will get more recognition and credibility than non-ISO certified organizations in the world's marketplace. Documentation can confirm consistency in an organization (Maynard et al., 2003). On the other hand, ensuring consistency in quality at any level via ISO 9000 or ISO 17025 does not mean high quality. The procedures of the ISO standard do not show actual quality of the product or service (Goetsch \& Davis, 2010; Vlachos, Michail, \& Sotiropoulou, 2002; Heizer \& Render, 2011). Thus, the ISO accreditation can be seen as a thereshold or a minimum quality level to be accepted in the market.

The negative or insignificant effect of ISO 17025 accreditation existence on laboratory performance may come from the reason of acquiring the accreditation being customer or supplier requirement, advertisement, and marketing gimmick purposes. ISO 17025 accredited laboratories may not give importance to customer satisfaction, employee fulfillment and quality of the product, service or process.

Laboratories who attempt to accreditation under the ISO 17025 standard face challenges of education and validation of tools and methods (Beckett and Slay, 2011). Top management support is important to improve employee fulfillment, consistency, reliability and accuracy of laboratory measurements, quality performance and customer satisfaction. Providing necessary training to employees can increase awareness about and commitment to produce quality products. Therefore, adequate training on quality and management support should be given to manufacturing and EMC laboratories to improve quality and laboratory performance.

The results of the analysis were discussed with some representatives of the participant laboratories and designers of the experiments. They claim that most laboratories try to implement ISO 17025 accreditation of quality management system. On the other hand, the laboratories with low endorsement avoid ISO 17025 accreditation due to its high financial cost. This result is consistent with Cooper, Moeller, \& Kronstrand's (2008) claim. Closely monitoring design, planning and implementation stages of ISO 17025 accreditation of quality management system for three to four years is highly recommended for practitioners.

Globalization increases the need for credibility of the laboratory. ISO 17025 accreditation can improve recognition. On the other hand, achieving accreditation requires considerable 
amount of financial resources for laboratories. Furthermore, the quality assurance system implementation can increase bureaucracy through complicate updated records. It requires extensive human resources tasks. Thus, it is difficult, time-consuming and costly (Vlachos, Michail, \& Sotiropoulou, 2002).

The extensive huge quantity of documentation developed for fulfilling the requirement of the standard can cause problem of redundancies of information in multiple documents. This leads to contradictory directives to its users. Especially, process changes should be modified in related multiple documents but the corrections are not usually done in every document. This causes inconsistency of the information, contradiction, and thus, important nonconformities in the system. If the members of the personnel follow different instruction for the same task, the performance of the laboratories will reduce (Zaretzky, 2008). When a process is performed incorrectly, technical validity of the results of the laboratory will reduce (Maynard, Foster, \& Hall, 2003). These problems can be remedied by implementing an enterprice resource planning (ERP) system with a common database. Monitoring documents, updating changes in the process, maintaining reliable, consistent, timely and accurate data and information throughout the laboratory can be achieved efficiently and effectively with an ERP system as well.

Employees of the laboratories can resist to the quality management implementation since their laboratories have already performed their technical work in a proper way before implementing the ISO 17025 Standard. Thus, employees may not commit to the requirements of the standard (Zaretzky, 2008).

The important factors for laboratories in seeking accreditation are motivation and determination (c.f. Malkoc \& Neuteboom, 2007). Top management commitment to quality is crucial to give adequate resources and to motivate the employees for their participation. Training should improve knowledge and skills of the employees for imlementing of quality management and accreditation successfully. There should be a common understanding of accreditation, its purpose and its process in order to get the maximum benefit from the efforts of accreditation.

Certification and accreditation may provide recognition and reputation of the laboratory both in their country and in the global economy. However, if a laboratory applies to ISO 17025 certification for solely marketing purpose without total quality management focus, it will eventually lose their clients, credibility, competitiveness, and profitability.

The main reason for adopting accreditation is the marketing strategy due to high financial responsibility of being accredited (Cooper et al., 2008; Goetsch \& Davis, 2010). Implementing quality management in laboratories brings additional time, effort and cost as this happens to all organizations. Some laboratories may be ISO 17025 accredited for merely gaining a marketing advantage rather than other motivations such as improving reliability, accuracy and consistency of their laboratory measurements. Such accredited laboratories do not get these benefits of ISO adoption due to their inappropriate motivations for adopting the accreditation.

The results of the study are supported by (Zaretzky, 2008)'s and (Uras, 2009)'s claims. The reasons of failure of ISO 17025 accreditation implementations of the laboratories in Turkey for improving quality, effectiveness, and performance of laboratories may be as follows: There may be errors in the auditing by the registrar of the laboratories in Turkey. Some certification bodies and their personnel may overlook the evaluation process instead of 
auditing with respect to the requirements of ISO 17025 accreditation in detail. In addition, some certification bodies and their personnel may not be honest and impartial in auditing. These can result in issuing the accreditation to the laboratories unfairly. Thus, certification bodies and their personnel may not audit effectively or ethically. Some certification bodies and the laboratories in Turkey may lack ethical guidelines in the audits and the accreditation process implementation to pursue their missions. In addition, some laboratories may adopt ISO 17025 accreditation for solely gaining a marketing advantage without total quality management focus. Thus, some laboratories may get ISO 17025 accreditation although they are not qualified with respect to the requirements of the standard. Therefore, we suggest that conformity assessments of the registrars (i.e. certification bodies' organizations, personnel, and procedures) in auditing and awarding the certificate should be conducted more strictly and frequently by the accreditation body to minimize errors and to improve impartiality, consistency, effectiveness and accuracy of the awarding ISO 17025 accreditation. This will also ensure and improve credibility of the ISO 17025 accreditation. Moreover, we propose that all stakeholders in the audit and accreditation process implementation should give more importance to ethics, quality and continual improvement in their guiding principles so that the laboratories will improve their performances by means of adopting the ISO accreditation.

When the effect ISO 17025 accreditation on laboratory performance is examined in other countries, fruitful discussions and suggestions can be generated. Thus, we recommend researchers to reexamine the effect of ISO 17025 accreditation on performance in other countries. In addition, longitudinal study may provide trends in the relationship between ISO 17025 accreditation and laboratory performance.

\section{Conclusion}

This study examined the effect of ISO 17025 accreditation on laboratory performance in Turkey. The results show statistically negative or insignificant effects on laboratory performance. When a laboratory adopts ISO 17025 accreditation for merely gaining a marketing advantage, this wrong motivation brings the laboratory negative outcomes such as high unsatisfactory and suspicious laboratory measurements and low satisfactory laboratory measurements. On the other hand, the laboratory adopts ISO accreditation for such purposes of improving quality, reliability, accuracy and consistency of its products, services and processes, and customer satisfaction, the laboratory can improve its laboratory performance, customers' loyalty and competitiveness in the market.

We suggest that the accreditation body should control and assess competency and honesty of the organization and personnel of the certification bodies in audits more strictly and frequently to improve credibility, fairness, and effectiveness of ISO accreditation. In addition, we suggest that the accreditation body, certification bodies, and laboratories should more emphasize such issues as ethics, quality, and continual improvement in their guiding principles to improve the impartiality and competency of the audits as well as to have good motivations for ISO adoption, and to increase quality, reliability, accuracy, and consistency of laboratory measurements.

\section{References}

Ahmad, M., Khan, F. A., \& Ahmad, S. A. (2009). Standardization of Pathology Laboratories in Pakistan: Problems and Prospects. Clinical Biochemistry , 42, 259-262. 
Cooper, G., Moeller, M., \& Kronstrand, R. (2008). Current Status of Accreditation for Drug Testing in Hair. Forensic Science International , 176, 9-12.

Cortez, L. (1999). The implementation of accreditation in a Chemical Laboratory. Trends in Analytical Chemistry, 18 (9-10).

Ferrero, C., \& Casaril, M. (2009). Proficiency Testing Programs to Improve Traceability in Chemical Analysis. Measurement, 42, s. 1502-1509.

Goetsch, D. L., \& Davis, S. B. (2010). Quality management for organizational excellenceintroduction to total quality (sixth ed. b.). New Jersey: Prentice Hall.

Guntinas, M. B., De La, C., Wysocka, I., Quetel, C., Vassileva, E., Robouch, P., et al. (2009). Proficiency Test for Heavy Metals in Feed and Food in Europe. Trends in analytical Chemistry, 28 (4).

Hall, D. J., Maynard, S., \& Foster, S. (2003). ISO 17025 Application within Racing Chemistry: A Case Study. Technovation, 23, 773-780.

Heizer, J., \& Render, B. (2011). Operations Management. New Jersey: Prentice Hall.

Iglicki, A., Mila, M. I., Furnari, J. C., Arenillas, P., Cerutti, G., \& Carballido, M. (2006). Accreditation Experience of Radioisotope Metroloji Laboratory of Argentina. applied Radiation and Isotopes, 64, 1171-1173.

ILAC (International Laboratory Accreditation Cooperation). (2010). htpp://www.ilac.org ISO/IEC-17025. (2010). General Requirements of Testing and Calibration Laboratories. Geneva, Switzerland: International Organization for standardization.

ISO-13528. (2005). Statistical Methods for Use in Proficiency Testing by Interlibrary Comparisons.

ISO-9000 . (2010). Quality Management Systems: Fundamentals and Vocabulary: htpp://www.iso.org

Korun, M., \& Glavic-Cindro, D. (2009). An Analysis of the Causes of Discrepant Results in Proficiency Tests in a Testing Laboratory. Applied Radiation and Isotopes , 67, 683-686.

Malkoc, E., \& Neuteboom, W. (2007). The Current Status of Forensic Science Laboratory Accreditation in Europe. Forensic Science International , 167, 121-126.

Maynard, S., Foster, S., \& Hall, D. J. (2003). ISO 17025 Application within Racing Chemistry: A Case Study. Technovation, 23, 773-780.

Raposo, F., Rubia, M. A., Borja, R., Alaiz, M., Beltran, J., Cavinato, C., et al. (2009). An Interlaboratory Study as Useful Tool for Proficiency Testing of Chemical Oxygen Demand Measurements Using Solid Substrates and Liquid Samples with High Suspended Solid Content. Talanta , 80, 329-337.

TSE. (2010). Turkish Standard Institution. htpp:/ / www.tse.org.tr

TSE. (2010). Turkish Standard Institution Inter-laboratory Comparison Test Program- 2009 Final Report. Gebze.

TUIK. (2010). Turkish Statistics Association. htp://www.tuik.gov.tr

TURKAK. (2010). Turkish Standard Institution Inter-laboratory Comparison Test Program. htpp://www.turkak.org.tr

Uras, F. (2009). Quality Regulations and Accreditation Standards for Clinical Chemistry in Turkey. Clinical Biochemistry, 42, 263-265.

Vlachos, N. A., Michail, C., \& Sotiropoulou, D. (2002). Is ISO/IEC 17025 Accreditation a Benefit or Hindrance to Testing Laboratories? The Greek Experience. Journal of Food Composition and Analysis , 15, 749-757.

Zaretzky, A. N. (2008). Quality management systems from the perspective of organization of complex systems. Mathematical and Computer Modelling , 48, 1170-1177. 


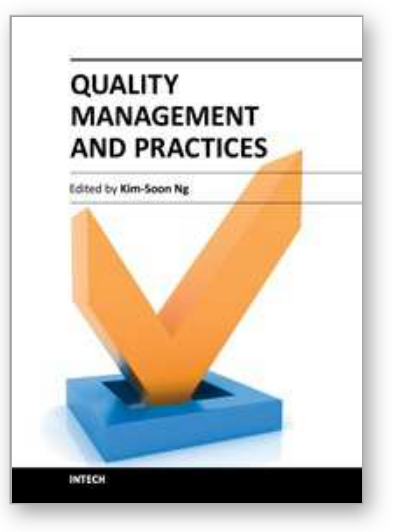

\author{
Quality Management and Practices \\ Edited by Dr. Kim-Soon Ng
}

ISBN 978-953-51-0550-3

Hard cover, 254 pages

Publisher InTech

Published online 27, April, 2012

Published in print edition April, 2012

This book is comprised of a collection of reviews and research works from international professionals from various parts of the world. A practical approach to quality management provides the reader with the understanding of basic to total quality practices in organizations, reflecting a systematic coverage of topics. Its main focus is on quality management practices in organization and dealing with specific total quality practices to quality management systems. It is intended for use as a reference at the universities, colleges, corporate organizations, and for individuals who want to know more about total quality practices. The works in this book will be a helpful and useful guide to practitioners seeking to understand and use the appropriate approaches to implement total quality.

\title{
How to reference
}

In order to correctly reference this scholarly work, feel free to copy and paste the following:

Esin Sadikoglu and Talha Temur (2012). The Relationship Between ISO 17025 Quality Management System Accreditation and Laboratory Performance, Quality Management and Practices, Dr. Kim-Soon Ng (Ed.), ISBN: 978-953-51-0550-3, InTech, Available from: http://www.intechopen.com/books/quality-management-andpractices/iso-17025-quality-management-system-accreditation-and-laboratory-performance

\section{INTECH}

open science | open minds

\section{InTech Europe}

University Campus STeP Ri

Slavka Krautzeka 83/A

51000 Rijeka, Croatia

Phone: +385 (51) 770447

Fax: +385 (51) 686166

www.intechopen.com

\section{InTech China}

Unit 405, Office Block, Hotel Equatorial Shanghai

No.65, Yan An Road (West), Shanghai, 200040, China

中国上海市延安西路65号上海国际贵都大饭店办公楼405单元

Phone: +86-21-62489820

Fax: +86-21-62489821 
(C) 2012 The Author(s). Licensee IntechOpen. This is an open access article distributed under the terms of the Creative Commons Attribution 3.0 License, which permits unrestricted use, distribution, and reproduction in any medium, provided the original work is properly cited. 